\title{
EL IMPERIALISMO EN TRAJANO (98-117 d. de C.): LA GUERRA Y LOS SIMBOLOS DEL PODER
}

\author{
Alejandro Villalobos Martínez*
}

\section{RESUMEN}

El propósito del presente estudio es analizar, a través de las fuentes, las causas que explican el exacerbado deseo del emperador Marco Ulpio Trajano, por expandir los territorios mediante guerras extremas, dándole continuidad a un ciclo de expansión romana cercano a los cuatro ciclos, y determinar cuáles son los símbolos y claves que caracterizan su poder. Así, Trajano gobernará entre el 98 y el 117 d. de C., siendo el último emperador que privilegia la guerra victoriosa por sobre la Paz Augustea.

Palabras claves: Imperialismo, guerra, expansión, símbolos de poder, ejército, arquetipo,

\begin{abstract}
The intention of the present study, it is to analyze through the sources, the causes that explain the trembling desire of emperor Marc Ulpio Trajan, to expand the territories by means of extreme wars, giving continuity to a cycle of Roman expansion near the four cycles, and to determine as they are the key symbols and that characterize their power. Thus, Trajan will govern between the 98 and the $117 \mathrm{~d}$. of C. being the last emperor who privileges the victorious war by on Augustea Peace.
\end{abstract}

Keywords: Imperialism, war, expansion, symbols of power, army, archetype.

\section{INTRODUCCION}

La civilización romana hacia el siglo II d. de C. había alcanzado su máxima extensión territorial, literalmente el mar mediterráneo se había convertido en un verdadero lago de pleno dominio, al que orgullosamente le denominaban Mare Nostrum. Donde convergían pueblos y culturas diversas, todas unificadas por una fuerza centrípeta llamada Roma, ubicada en el centro de este mar. Roma, consciente de su dominio y de su poder civilizador, reconoce su influencia como potencia rectora del mundo mediterráneo. A la llegada de los Antoninos, la ecúmene era dominada por Roma, la mayor parte de Europa, el oeste de Asia y el norte de África conforman el orbis romanus. Roma ha configurado un imperio tricontinental y mundial, es el mundo, señalaba Elio Arístides, “...la ciudad gobierna toda la tierra entera, ya más no cabe admirarse de que toda la ecúmene sea mandada por la ciudad". El imperio vivía una época de esplendor cultural que ha sido reconocido entre la historiografia tradicional, y las propias fuentes resaltan el legado civilizador y protector del bienestar romano, quien transforma el territorio y la vida social de todo el género humano, civilizando, integrando y romanizando la humanidad ${ }^{2}$.

La consolidación de este imperio a través de los siglos fue el legado de diferentes modelos políticos imperiales y republicanos. Bajo estos parámetros, en el presente trabajo buscamos destacar la personalidad, obra

* Profesor de Historia y Geografia, Magister en Historia por la Universidad de Concepción y docente de Historia Antigua y Medieval de la Universidad San Sebastián.

Aristides, A. Roma, XXVI,9.

2 Estrabón, Geografia, III, 15, señala: Los turdetanos se han asimilado perfectamente al modo de vida de los romanos y ni siquiera se acuerdan de su propia lengua. La mayoria se ha convertido en latinos... han recibido a romanos, de modo que poco les falta para ser romanos..." También Arístides, A. Roma, XXVI,28-30, señala: "En este momento, los límites alcanzados por el imperio en su estado actual son tales que es imposible medir el espacio que abarca... no hay nada que se os escape, ninguna ciudad, ninguna población, ningún puerto, ninguna región..., así toda la ecúmene unida canta con mayor perfección que un coro, rogando conjuntamente para que este imperio perdure por toda la eternidad". 
y concepción imperialista del emperador Trajano. El propósito es analizar a través de las fuentes las causas que explican el exacerbado deseo de Trajano por expandir los territorios mediante guerras extremas, continuando un ciclo de expansión cercano a los cuatro ciclos, y que caracterizan su obra con símbolos genuinos y propios de su poder. Así, Trajano gobernará entre el 98 y el 117 d. de C., siendo el último emperador que privilegia la guerra victoriosa por sobre la Paz Augustea.

\section{BIOGRAFIA}

Marco Ulpio Trajano ${ }^{3}$, nacido en Hispania, en el año 53 d. de C., en la provincia más romanizada del imperio, en Itálica. Fue el primer provincial que llegó a ser emperador, probablemente no era descendiente de los colonos itálicos asentados en la ciudad, sino perteneciente a una familia Turdetana, plenamente romanizada, de cuyo seno su padre fue el primero en convertirse en senador. Fue adoptado como emperador por $\mathrm{Nerva}^{4}, \mathrm{y}$ tanto la historiografía antigua como la moderna le han sido muy favorables, especialmente en lo que respecta a política exterior y las relaciones con los órganos internos de administración, especialmente el Senado, que en el año 100 le otorgó el título de Optimus Princeps, ${ }^{5}$ el mejor, como valoración a un príncipe que ha llevado al imperio a su máxima expresión y extensión, y en concordancia con las aspiraciones imperialistas del Senado, que veía las conquistas como una necesidad de sobrevivencia y beneficencia para el espacio cultural romano ${ }^{6}$. Además, Trajano se presenta como modelo de soldado, emulo de Alejandro Magno ${ }^{7}$, respondía al ideal de buen príncipe conquistador y con capacidades bélicas superiores, como líder carismático, demostrando sus dotes de estratega ${ }^{8}$. Con Trajano Roma alcanzará el apogeo de su poderío militar y la máxima extensión territorial'.

Las fuentes coinciden en su mayoría en la beneficencia desarrollada por este emperador, con escasas críticas a su administración, razón que explica la revisión positiva que la historiografía ha desarrollado de su obra hasta su muerte, que se produce al regreso de oriente el 11 de agosto de 117 .

\section{CARACTERISTICAS PERSONALES}

El análisis de la personalidad de este emperador ha sido objeto de innumerables interpretaciones desde el mismo momento de su deceso, por lo que su modelo imperial traspasó las barreras del tiempo, dando origen a miradas disímiles en las edades Media, Moderna y Contemporánea ${ }^{10}$.

3 Sobre la figura de Trajano la bibliografia es prolífica, existen algunos estudios ya clásicos y otros recientes de los que destacamos y hemos trabajado: Cizek, E., L'èpoque de Trajan. Circonstances politiques et problemas ideologiques, Paris, 1983; Bennet, J., Trajan Optimus Princeps, Life \& Time, London - New York, 1997, con abundante bibliografia. Una bibliografia comentada sobre su reinado encontrará el lector en Waters, K., "The Reign of Trajan and its Place in Contemporary Scholarship (1960-1962)" en ANRW II. 2 (1975) 381-431. En González, J., (eds), Imp. Caesar Nerva Traianus Augustus, Sevilla, 1993. Recientemente González, J. (eds) Trajano Emperador de Roma, Roma "L'Érma" di Bretschneider, 2000.

4 Aurelio Víctor, De Caesar, XIII, nos indica: "Nerva adoptó en el seno de su familia a Ulpio Trajano, aunque nacido en Itálica, ciudad de hispania, era un personaje de muy alto rango proveniente de una familia consular".

5 Plinio el Joven, Panegírico, 88,4-6. También Hidalgo de la Vega, $\mathrm{M}^{2}$. El intelectual, la realeza y el poder político, Universidad de Salamanca (eds), Salamanca (1995), p.113, señala que la denominación de Optimus Princeps se atribuía a hombres insignes como Augustus que tiene origen sacral, y está en desacuerdo con otorgárselo a Trajanos que sólo es una creación intelectual de Plinio, Con una opinión diferente véase a Herrera C., H.; "Príncipe e imperio en el panegírico de Trajano" de Plinio el Joven, en Semanas de Estudios Romanos VII-VIII (1996), pp. 277285, quien destaca las virtudes de Trajano que justifican la denominación de Optimus Princeps, p. 280. Michelotto, P., Aspetti e problema dell'età traiana, Teti Editore, Milano, 1994, p. 30, se refiere al concepto de óptimo como un concepto feliz, pero ambiguo, ya que connotaba un sentido "dcmocrático" que resaltaba las virtudes del nuevo emperador, en contraposición al pasado de los Flavios, con una fuerte carga ideológica que buscaba lcgitimar el poder del príncipe, como símil de Júpiter óptimo máximo.

Birley, A., Adriano. La biografía de un emperador que cambió el curso de la historia, Peninsula, Barcelona, 2003 , p. 99.

Nenci, G., "L'imitatio Alexandri", en Polis, 4 (1992), pp.173-186.

- Plinio el Joven, El Panegírico, XIII, 50-51. señalaba: "Había hecho honores a su fama al marchar a pie con sus hombres en toda la campaña, vadeando ríos con ellos y enviando a veces deliberadamente informes falsos sobre ataques inminentes del enemigo para que los soldados se mantuvieran en buenas condiciones".

- Aurelio Victor, De Caesar, XIII, 2, nos informa de Trajano que "... fuc el primero y casi el único de los emperadores que llevó el imperio romano más allá del Danubio, sometiendo y reduciendo a provincia a los pueblos Dacios."

10 Gil, J., "Trajano en la Edad Media", en González, J. (eds) Trajano emperador (cit), pp. 155-178, quien presenta un análisis de la visión transmitida del emperador desde la antigüedad tardia hasta los siglos medievales, resaltando la idea de la doble vertiente en Trajano: Primero como el "perseguidor de cristianos", y en segundo lugar el de "óptimo princeps", ideas que se desprenden a partir de las opiniones de los padres de la Iglesia, Orosio, San Jerónimo, San Clemente, entre otros, los que sin duda forman parte de la leyenda de Trajano. Respecto a la visión de Trajano en tiempos modernos véase Maestre, J., "Trajano y los humanistas", en González, J. (eds) Trajano emperador (cit), pp. 313-361, quien profundiza en la figura paradigmática de Trajano en el Renacimiento, cuya figura es utilizada especialmente por los humanistas en España como modelo político, destacándolo como un "compatriota" que había llegado a ser un virtuoso emperador de Roma.

Revista de Historia, año 16, vol. 16(1), 2006, pp. 35-46 
De acuerdo a las fuentes analizadas, Trajano poseía temperamento y serenidad, el que se manifiesta propenso al trato generoso, pero implacable y severo cuando el sentido de la autoridad y la protección del Estado lo requiriera ${ }^{11}$. Asimismo, éstas destacan que las virtudes de Trajano no son simplemente humanas, sino que forman parte de los designios divinos que este príncipe encarnaba, como un rey piadoso, observante y complaciente de los deseos de los dioses, siendo éstas las primeras virtudes y obligaciones de todo rey ideal, como cree Dion de Prusa ${ }^{12}$.

Para Santiago Montero, la personalidad de Trajano, proclive a la beneficencia, la sintetiza cabalmente al señalar que "es más romano que César y tan romano como Augusto. Sus dos obsesiones son el campo y la conquista. Guerra y agricultura, con toda la profundidad del campesino y con todo el ímpetu del conquistador"13.

Por otra parte, las fuentes lo presentan como el ciudadano que desea disfrutar de las bondades de la ciudad, pero su mayor preocupación era estar frente a las tropas, conduciendo el ejército como general, no olvidando ser un buen príncipe y benefactor en la ciudad. Trajano es quien construye su imperio frente al enemigo, la gloria de Roma está frente a los bárbaros o los aliados. En el exterior los pueblos aliados solicitarán su justicia y reconocerán en él su majestad, no por haberlos vencido solamente, sino más bien por haberlos incorporado a la civilización.

\section{EL GOBIERNO}

Las fuentes literarias que abordan el período imperialista de Trajano no siempre presentan claves que permitan análisis históricos más exhaustivos en el plano político ${ }^{14}$. Sin embargo, las fuentes disponibles y la historiografía coinciden en señalar que la administración política, económica y militar del imperio en tiempos de Trajano tuvo como eje central la expansión de Roma, impulsando una dominación agresiva frente a sus vecinos, tendiente a obtener ventajas políticas y económicas a partir de la obtención de riquezas. Las guerras dacias en el oriente, la incorporación de reyes indígenas al imperio, la extensa labor edilicia en las provincias, la restauración y construcción de caminos, son el fiel reflejo de que Trajano buscaba beneficiar a todo el imperio y alcanzar la grandeza en la conquista. Asimismo, utilizó su magnificencia como un eficaz método propagandístico, sin embargo, su administración económica producto de su intensa labor edilicia resultó catastrófica para el erario estatal ${ }^{15}$.

Por otra parte, el gobierno de Trajano presenta ciertas contradicciones históricas. En primer lugar, es el símbolo de la felicitas temporum, es la época de mayor crecimiento y prosperidad y la época donde llegan las mayores riquezas y multiplicidad de costumbres y, en segundo lugar, se señala como una de las causas de la decadencia de los tiempos ${ }^{16}$ y también como la época de grandes gastos e inversiones del Estado Romano.

La política interna tuvo como principal eje la armonía y concordia en las relaciones con el Senado y la aristocracia provincial, hecho de especial importancia, ya que ha servido a la historiografia para resaltarlo co-

11 Frente a los cristianos Plinio el Joven, Epistolas X, destaca que impide la condena sin comprobar el delito de traición al emperador. También Plinio, Panegírico, XVI, 4-5, destaca la fuerza y el poder de Trajano para enfrentar a rivales y hacer justicia. En un estudio pormenorizado del sustrato filosófico y de las ideas políticas del gobierno de Trajano véase a Montero, S., De Caliclés a Trajano. Estudios sobre historia política del mundo antiguo, Instituto de Estudios Políticos, Madrid, 1948, esp. pp.185-186, quien sintetiza el estilo de gobierno de Trajano marcadamente senequista y estoicista.

12 Dion de Prusa, Discursos, I, 16-17, señala: "El buen rey, en primer lugar, es observante de los dioses, tributando honor al culto divino. Porque no es posible que un hombre justo y bueno preste obediencia a ningún otro hombre antes que a los dioses, absolutamente justos y buenos".

13 Montero, S., op.cit. De Caliclés a Trajano, pp.187 y 191, señala que en él se destaca "la madurez para conducir el imperio: no hay en aquél el ímpetu que confiere a Alejandro la magnitud de semidiós, es un soldado que procede en todo como un experto campesino, que piensa y medita, un hombre maduro".

14 En torno a las fuentes para el período de los Antoninos un exhaustivo análisis realiza de Le Gall, J. y Le Glay, M., El Imperio Romano, El alto imperio, I, Akal 1995, Madrid, pp.346-398, esp. p. 346, quienes señalan que el período de apogeo del imperio romano es la época de los Antoninos, sin embargo su historia es relativamente mal conocida debido a que las fuentes de que disponemos presentan muchas deficiencias, algunas inconclusas o poco fiables, lo que hace necesario recurrir a las ciencias auxiliares, tales como la numismática, la epigrafia, papirología. La fuente más confiable que permite analizar la política imperialista de Trajano es el Panegírico de Trajano y el libro X de sus Epistolas, también Juvenal, Las Sátiras, los Epigramas de Marcial, Dion Casio, y las opiniones aisladas de escritores de los siglos IV y V Aurelio Víctor, Eutropio, Tertuliano y otros. Sánchez, M., El Alto Imperio Romano (14 al 235 d.C.), Síntesis, Madrid, 1998, pp. 24-27, presenta un detallado análisis de las fuentes literarias griegas y latinas para el estudio del imperio.

15 Petit, P., Historia de la Antigüedad, Labor, Barcelona, 1982, pp. 329-331.

16 González-Conde, Mª P., La Guerra y la Paz con Trajano y Adriano, Fundación Pastor de Estudios Clásicos, Madrid, 1991, pp. 133-134, la felicitas temporum es una época de una sensación de abundancia, de prosperidad, y que se plasma en realizaciones concretas: La asistencia social, es el caso de los Alimenta, y el de las Construcciones Públicas, también véase PANI, "Il Principato Dai Flavi ad Adriano", en Storia di Roma, 2, L'Imperio Mediterráneo. I, principe e il mondo, Einaudi,Torino, 1991, pp. 275-276. 
mo "buen gobernante", asistía a sus sesiones, y le dio preponderancia a los senadores hispánicos ${ }^{17}$, relación que le otorgó dividendos políticos, obteniendo el apoyo a su proyecto imperialista, característica del Senado en época republicana o, al menos, influida por éste ${ }^{18}$. Asimismo, cl éxito en el campo de batalla entregaba al orden senatorial la seguridad y la proyección de la política imperialista de Trajano.

Paralelamente, el gobierno alcanzó un carácter religioso y aristocrático, relacionando a Júpiter y el emperador $^{19}$. Trajano le proporciona cierta mística religiosa y carismática, que le facilita una legitimación al régimen aristocrático. Plinio el Joven, en el Panegírico de Trajano ${ }^{20}$ fortalece y acrecienta esta idea, como el emperador "elegido" por el pueblo y sus dioses, donde su gobierno es un regalo de los dioses". Este es un gobierno de la rectificación de errores del pasado, cuya clave es la libertad con justicia. Trajano encarna el imperio del bien y del bienestar ${ }^{22}$, representa un nuevo "estilo", Trajano establece un cambio en la política interna del imperio, donde él es un padre y un ciudadano que valora el espíritu republicano ${ }^{23}$. También Dion de Prusa expresa sus elogios a Trajano, a quien tiene como arquetipo de buen gobernante, mostrando la imagen del buen pastor, siempre preocupado por su rebaño ${ }^{24}$.

Finalmente, entorno al gobierno, destacamos que su estilo de administración es propio y singular, de acuerdo a las fuentes como Plinio, que en medio de su acervo lingüístico y literario destaca la beneficencia y el mejoramiento de la vida de los habitantes del imperio ${ }^{25}$; el emperador es visto por las fuentes como el constructor de un imperio, de ciudadanos felices y dichosos, es en definitiva la impronta que caracteriza y simboliza políticamente el gobierno de Trajano.

\section{TRAJANO EL ARQUETIPO DE EMPERADOR Y CIUDADANO}

Trajano representa para su época un arquetipo hecho realidad, y el líder necesario para gobernar el imperio, mediante la conquista y la anexión de territorios ${ }^{26}$. Trajano militar, proclamado por sus tropas, cuenta con el apoyo y la confianza de un ejército. Su personalidad, su carisma y su espíritu le permiten dar la conducción a la conquista; Trajano como jefe militar y Pontifex maximus impone a la tropa su poder supremo y religioso ${ }^{27}$,

17 Christol, M. y Nony, D., De los orígenes de Roma a las invasiones bárbaras, Akal, Madrid, 1991, p.186, proporcionan un análisis detallado de la promoción de los Hispanos en el Senado, quienes se acaparan magistraturas (treinta consulados entre 97 y el 138) y las más altas funciones del Estado, gobiernos provinciales y mandos extraordinarios.

18 En Geza, A., "Trajano Padre y la Inscripción del Nimfeo de Miletos", en González, J. (eds.) Trajano emperador (Cit.) pp.12-18, a propósito de la familia del Emperador, señala que fue "adoptado por Nerva, y por esto destinado como sucesor al trono gracias a su éxito contra su rival y compatriota hispánico M. Cornelius Nigrinius Curiatius Maternus, quien también aspiraba al mismo poder".

19 Plinio el Joven, Panegírico, I, 4-5, profundiza en la participación divina que supone la elección de Trajano: "Nuestro príncipe fue nombrado por decisión divina, no por la fuerza oculta de los hados". También Herrera C., H., op. cit. (Príncipe), p. 280, sostiene que Plinio busca demostrar que Trajano es el heredero elegido de Júpiter y el responsable ante los dioses.

20 Plinio el Joven, sobrino de Plinio el Viejo o El naturalista, nacido en Como en el año $62 \mathrm{~d}$. de C., discípulo de Quintiliano, fue tribuno militar, tribuno de la plebe, pretor, prefecto militar; nombrado por Trajano Gobernador Bitinia, en el Asia Menor. Era amigo personal del emperador, de quien tenía toda su confianza para reorganizar esta provincia que estaba en gran desorden. Su principal obra es el Panegírico a Trajano, para estudiar la personalidad de Trajano, obra que la historiografia moderna ha criticado y cuestionado por el excesivo beneplácito y encomio a la obra política de Trajano, escrita cuando Plinio pertenecía al círculo más cercano del emperador, destacando el sublime carácter literario de esta obra. Al respecto véase Hidalgo de la Vega, M $^{\mathrm{a}}$., op. cit.,(El Intelectua)1, esp. pp.105-106, quien scñala que Plinio sólo fue un "oportunista político", ya que también participó del gobierno de Domiciano, siendo un abierto colaboracionista, y luego cuando Trajano llega al poder lo denigra y crea la figura de un soberano ideal de carácter constitucional, que respeta las leyes y crea un vinculo republicano. Cfr. Giovannini, A., "Oposition et Résistances a l'empire d'Auguste a Trajan, Entretiens XXXII", en Fondation Hardt, Vandceuvres- Genève, 1986, pp. 221-236, quien analiza profusamente la actividad política e ideológica de Plinio y considera que fue el principal delator de Domiciano; olvidando las ayudas politicas recibidas de Domiciano, denosta a Domiciano para exaltar a Trajano.

21 Montero, S., "Trajano y la adivinación. Prodigios, oráculos y apocalíptica (98-117 d. de C." en Gerión, pp.13-24, presenta un extenso capítulo muy detallado de la importancia que adquiere en Trajano la convicción que su rango fue "elegido por los dioses", por lo que se emiten monedas con la leyenda de Providentia, que literalmente pretende mostrar que los dioses han escogido al mejor para gobernar.

22 Plinio el Joven, Panegírico, XLVI, 6-8. Michelotto, P., op. cit. (Aspetti e problemi), pp.7-15, señala que con Trajano se restablecen las virtudes de la Roma imperial, Trajano representa la inflexión en la libertad perdida en tiempos de Domiciano.

23 Herrera C., H., op. cit. (Príncipe), pp. 277-279, resalta la figura de Plinio como el constructor de la imagen política de Trajano, para él Trajano es el "prototipo ideal de ciudadano y de emperador".

24 Dion de Prusa, Discursos, 43-44.

25 Plinio el Joven, Panegirico, XL, 2-5.

26. Plinio el Joven, Panegirico, IV, 4-5, se refiere señalando que: "está dotado aquél de la voluntad y del mudo arbitrio con que se gobiernan los mares y las tierras, la paz y las guerras".

27 Montero, S., op cit. (Trajano y la adivinación) p.171, señala que la política imperialista de Trajano se veía reforzada al consentimiento que los dioses le otorgaban, por lo que Trajano utilizaba todos los signos que los oráculos le proporcionaban para dirigir la guerra y la tropa, siendo sus concepciones religiosas y místicas claves fundamentales de su poder.

Revista de Historia, año 16, vol. 16(1), 2006, pp. 35-46 
Plinio se deslumbra con este carácter y ensalza la valentía y la justicia del emperador en el campo de batalla. ${ }^{28}$ Trajano distingue los deseos e intereses del ejército, lo conoce en su esencia y participa de la vida cotidiana de ellos, se mezcla con ellos como uno más, es más partícipe de las tropas que del palacio imperial, su espíritu belicoso es innegable ${ }^{29}$, demostrando a temprana edad sus condiciones y capacidades militares y administrativas al mando de la X Fretensis, como legado de la legión Judea, el año '66, y luego, gobernador de Siria en la década del 70, destacando como general victorioso ${ }^{30}$.

Plinio destaca en su panegírico la labor civilizadora y benefactora de Trajano en su imperio, lo presenta como el restaurador ${ }^{31}$, que restituye la armonía y el entendimiento entre el buen príncipe y los ciudadanos, proporciona la seguridad interior, le restituye la confianza y la dignidad ${ }^{32}$, reestablece el comercio, producto de la paz interior y la protección dada por el poder de sus tropas y el respeto a los ciudadanos. Plinio cree que en el panegírico debe mostrar a los sucesores de Trajano el camino que debían seguir, especialmente respecto al espíritu guerrero y conquistador ${ }^{33}$, resaltando las virtudes humanas y como princeps. También, Dion de Prusa resalta la figura del emperador como un hombre honrado, bueno, de naturaleza moldeada por la educación divina ${ }^{34}$, un modelo de príncipe.

La visión geopolítica del espacio imperial se presenta como un proyecto de integración de provincias bajo el dominio del emperador, donde la persona de Trajano es quien proporciona protección, justicia y clemencia frente a los errores del pasado, él es el líder de un proyecto universalista ${ }^{35}$, quien facilita indirectamente el intercambio interracial o étnico entre los pueblos del imperio ${ }^{36}$ a través de la dominación territorial.

\section{LA GUERRA Y EL EJERCITO}

El deseo de conquistar tierras y expandir el dominio romano es una temática fundamental para la comprensión del mundo antiguo y en particular de la Roma Imperial, y muy estudiada desde diferentes perspectivas historiográficas, cuya génesis se encuentra en la época republicana, período de construcción espacial del imperio, a través de una extensa política imperialista de $\operatorname{Roma}^{37}$ y de un expansionismo casi imparable iniciado con las guerras púnicas, en el siglo III a. de C. ${ }^{38}$, donde Roma aseguraba el dominio de la cuenca occidental del mediterráneo ${ }^{39}$.

28 Plinio el Joven, Panegírico, XII,3-4, destaca la relación de Trajano en el Danubio con naciones salvajes, ante una naturaleza hostil y despiadada frente a los bárbaros.

29 Plinio el Joven, Panegirico, XVI, 5.

3o Marcial, Epigramas, XII,8, señala respecto a las virtudes del emperador: "Un caudillo tan grandioso, veía a un soldado valeroso y joven aguerrido...".

31 Plinio el Joven, Panegirico, XXIX,2-3, nos orienta al señalar "su obra civilizadora... con su autoridad, consejo y protección, construyó carreteras, abrió puertos, restituyó los caminos de tierra adentro, y la comunicación de mar a tierra y de tierra a mar..."

32 Plinio el Joven, Panegírico, L, 6-7. "Tal es la bondad del príncipe, tal es la seguridad de nuestro tiempo, que nos estima dignos de los bienes principescos y nosotros tememos parecer dignos". Michelotto, P., op. cit., (Aspetti e problemi), pp.7-17, destaca la restauración ideológica que proporciona el nuevo emperador, que no sólo representa a los generales.

33 Plinio el Joven, Panegírico, XIV,1-2, nos indica: "¿No fueron esos ejércitos cuando siendo un mozo incrementaste la gloria de tu padre con el laurel de la victoria sobre los Parthos y ya mereciste el nombre de Germánico...cuando recorriste todo el universo mundo...?"

${ }_{34}$ Dion de Prusa, Discursos, I, 34-36, Frente a Trajano ensalza sus virtudes, comparándolo con quien le precedió: "Quién no tendría por dichoso a un hombre tal y a su vida? ¿De qué tierras lejanas no vendrían a verle para aprender de él la excelencia y la bondad de su carácter? ¿Qué espectáculo más solemne que el de un rey noble y amante del trabajo? ¿Qué cosa mas agradable que un rey pacífico y amable que, deseoso de hacer el bien a todos, lo puede hacer? Así pues de forma muy sencilla he expresado las cualidades de un rey ideal".

35 Plinio el Joven, Panegírico, XXXII,1-2. " ...i que bien va a todas las provincias el haberse acogido a nuestra protección y a nuestra ley, puesto que les cupo en suerte un príncipe capaz de traer y llevar fecundidad de las tierras, ahora de aquí y ahora de allá, según las exigencias del tiempo y la necesidad, capaz de alimentar y auxiliar a una nación separada por el mar, como si fuera una porción del pueblo y de la plebe romana..!".

36 Ibidem, XXXII,2-3. "... Comunica el oriente y el occidente con intercambios mutuos de tal suerte que todas las naciones tengan noticias reciprocas de lo que producen y de lo que necesitan". También véase la opinión contraria de Le Gall, J. y Le Glay, M., op. cit. (Imperio), p.346, considera que Trajano nunca quiso la guerra para conquistar la Arabia Nabatea y para permitir el tráfico comercial procedente de la India atravesando el imperio parto y la Península Arábiga, ya que nunca los romanos le "atribuyeron mucha importancia al comercio exterior del Imperio."

37 Uno de los grandes especialistas del imperialismo romano Harris, W., Guerra e Imperialismo en la Roma Republicana: 327-70 a.C., Siglo XXI, Madrid, 1989, analiza los móviles que Roma posee para expandirse y conquistar el mediterráneo. Concluye que se debe a la mentalidad de la sociedad romana y a sus estructuras sociales de dos grupos: El sector aristocrático, quienes determinaron y condujeron la politica exterior, y sus deseos de gloria y de poder, el valor, la virtud, y la laus, el reconocimiento, la fama y la alta estima de sus conciudadanos. El otro grupo son los ciudadanos medios, que veían en la guerra y las conquistas una alternativa para el ascenso social, para obtener botines y bienes. En síntesis, Harris plantea que el Ethos romano fue esencialmente guerrero y una mentalidad imperialista muy racional y ofensiva.

38 Nicolet, C., Roma y la Conquista del Mundo Mediterráneo 264-27 a.C. 2. La génesis de un imperio, Labor, Barcelona, 1984, pp.771-775. Cfr. Buono-Core V., R., "La oceanopolítica y la geopolítica, ¿Claves para una comprensión del expansionismo romano entre los siglos VI y III a .de C.?", en Semanas de Estudios Romanos, VII-VIII (1996), Universidad Católica de Valparaíso, pp. 57 y 69.

39 Polibio, Historias, III, 4,10, señala respecto a la expansión conquistadora de Roma: "Es único hecho y único espectáculo, es decir, cómo, cuándo y por qué todas las partes conocidas del mundo conocido han caído bajo dominación romana". Bancalari M., A., "Lineamientos para el estu-

Revista de Historia, año 16, vol. 16(1), 2006, pp. 35-46 
Roma desarrolló durante prácticamente cinco siglos un imperialismo defensivo y ofensivo con múltiples causas $^{40}$. Heredero de esta política exterior es Trajano, reconocido por las fuentes y la historiografía actual como el último emperador conquistador e imperialista ${ }^{41}$, continuador de la Roma imperialista, que entre los siglos III y II a. de C. convirtió a Roma en la primera potencia mediterránea, temible por sus éxitos, que desarrollaba la virtud de su pueblo, y dotada de un ejército cívico superior ${ }^{42}$.

Para Trajano, la guerra externa otorgaba beneficios económicos y políticos. A la vez, se presenta como una defensa de la comunidad o de la patria, que permite mantener o acrecentar los beneficios de la paz, la guerra es vista como una actividad masculina y viril ${ }^{43}$. Así, la incorporación de nuevas provincias acrecentó no sólo el botín, sino que se transformaron en el mayor respaldo para su poder, su prestigio y estabilidad política $^{44}$, siendo la victoria exterior entendida como el vehículo de prosperidad interior, la guerra necesaria para alcanzar la paz ${ }^{45}$.

En el paradigma expansionista de Trajano no se puede soslayar el rol e importancia que adquirió el ejército en la historia romana. Este simboliza inequívocamente la grandeza de Trajano y de la propia Roma durante los siglos I y II. En este período alcanza su mayor esplendor, en su estructura y en sus éxitos militares, había llegado al apogeo de su organización, profesionalizado ${ }^{46}$. El ejército permitió la configuración y defensa del espacio imperial. Su principal misión era la guerra y la protección, seguida por el mantenimiento de la paz en el interior. El ejército realizaba numerosos servicios y se transformaba en mano de obra eficaz y relativamente tecnificada. Mantenía un cuerpo de ingenieros y arquitectos militares de primer nivel, siendo el artífice de las construcciones en el mundo romano ${ }^{47}$, también fue motor de la romanización del imperio, logrando el mayor impacto cultural en la población nativa, con la influencia en la llegada del ejército romano, cuyas legiones y tropas eran acompañadas por ciudadanos, comerciantes y gobernantes ${ }^{48}$, también cumple la tarea de una escuela de administración y de gobierno para los príncipes ${ }^{4}$.

Estaba compuesto por ejércitos provinciales, tropas de guarnición en Roma y flotas navales en Rávena, que

dio de la Historia Romana", en Limes 9-10 (1997-1998), Universidad Metropolitana de Ciencias de la Educación, pp. 170-184, presenta diversas reflexiones, propuestas y métodos de trabajo para reestudiar la historia romana como una historia universal.

40 En torno al concepto de imperialismo, la historiografia actual ha desarrollado importantes investigaciones con múltiples interpretaciones, una de ellas es presentada por Harris, W., op. cit. (imperialismo), también véase Nicolet, C., op. cit. (Roma) pp.771-775, quien explica los mecanismos de configuración del imperio a partir de la política de conquistas y anexiones de Roma. También Hammond, N. y Schulard, H., The Oxford Classical Dictionary, The Clerendon Press, Oxford, 1989, pp.750-751, quien desarrolla la idea del imperialismo como sinónimo de fuerza y poder de conquista y expansión territorial; presenta las tesis de Mommsen basada en el imperialismo defensivo (Roma conquista porque necesita defenderse de sus eventuales enemigos) y que también Roma conquista por razones económicas que le reportan beneficios a las clases politicas. Buono-Core V., R., op. cit. (La oceanopolítica), pp. 57-69, analiza las causas del imperialismo republicano, considerando que este proceso se puede datar hacia el siglo VI a. de C., y que se inicia con el "expansionismo romano", que a su vez es el resultado de la voluntad hegemónica que se manifestará en los siglos posteriores, particularmente en el mar, a lo cual se le denomina Oceanopolítica, rechazando explícitamente la tesis del expansionismo defensivo.

4. Villalobos, A., "La politica exterior de Trajano y Adriano (98-138 d. de C.): Concepciones geopoliticas y espaciales del Imperio Romano", Tesis inédita para optar al grado de Magíster, Universidad de Concepción, 2005, pp. 55-56, donde se analiza la visión de las fuentes frente al fenómeno de la guerra, con posiciones disímiles, exaltando la guerra como la paz, sin desconocer que en su mayoría, estas fuentes forman parte de la literatura oficial, y su posición favorable o en contra de la guerra, dependerá de la posición que ocupe tanto el emperador como el autor frente al poder.

42 Las virtudes ciudadanas, motores del imperialismo, exaltadas por Plinio, son analizadas por Herrera C., H., op. cit. (Príncipe e imperio) p. 281 , quien valora la admiración de Plinio por Trajano, que llega a decir que "quien ha de imperar sobre todos debe ser elegido de entre todos". Plinio el Joven, Panegírico, VII,6, Trajano es el restaurador de las tradiciones republicanas porque busca revivir estos modelos sociales, cs un arquetipo ciudadano modelo de virtud.

43 Martínez L, C., "Las mujeres y la paz en la historia", en Muñoz M. F. y López M., M. (eds) Historia de la Paz: Tiempos Espacios Actores, Colección monográfica Eirene 12, Universidad de Granada (2000), pp. 256-257, quien analiza profusamente la guerra y la paz en la identidad de género.

44 Pani, M., "Il Principato Dai Flavi ad Adriano", en Storia di Roma 2, (cit), pp. 275-276. También véase Mazzarino, S., L'impero Romano, I, Laterza, Roma-Bari, 1984, pp. 296-297, señala que las conquistas proporcionaban a Trajano el oro necesario para sostener el régimen en forma autoritaria.

45 Véase Mazzarino, S., op. cit. (L'impero), pp. 295-335, afirma que la política exterior de Trajano se justificaba con las conquistas de territorios que efectivamente aportaran oro al tesoro de Roma, ya que la conquista de zonas ricas proporcionaba tranquilidad al interior del imperio y en el limes.

46 Plinio el Joven, Panegírico, XVIII, 1, se refiere al esplendor que vivia el ejército desde la ascensión de Trajano y culpa a Domiciano por los males de Roma y del ejército. También Petit, P., La paz romana, Labor, Barcelona, 1976, pp. 5-62, p.6, se refiere en extenso a que cl ejército de los Antoninos es profesional, pero con un alto costo de mantención.

47 Véase Christol, M. y Nony, D., op. cit. (De los origenes), pp.157-169. También respecto a la funcionalidad del ejército del alto imperio en Sánchez, M., op. cit. ( El alto imperio), pp. 61-62.

${ }^{48}$ Dumayne, L., "The effect of the Roman environment of Hadrian 'wall: A pollen diagraman from fozy moss, Nortumbria", en Britania, 25 (1994), pp. 217-224. También Bancalari, A., "El Proceso de Romanización en Occidente. Factores y Consideraciones Teóricas", en Atenea, I, 477 (1998), Universidad de Concepción, pp. 63-86, destaca las funciones del ejército como elemento y factor divulgador de la cultura romana.

49. Le Glay, M., La grandeza y caida del imperio Romano, Cátedra, Madrid, 2002, p.111.

Revista de Historia, año 16, vol. 16(1), 2006, pp. 35-46 
contribuían a mantener la paz interna por medio de la flota y las escuadras provinciales que patrullaban a lo largo de las costas velando por la seguridad, desplazando y transportando a las legiones como apoyo logístico ${ }^{50}$.

No obstante las capacidades y virtudes, el ejército también presentaba dificultades para financiar y aprovisionar a la tropa, que era cada vez más distante de Italia ${ }^{51}$, situación que obligó a incorporar tropas y cuerpos auxiliares provinciales ${ }^{52}$, cuyo reclutamiento era más fácil y más barato ${ }^{53}$, paliando los déficit y el abastecimiento militar en las zonas más extremas y a la vez fomentando la regionalización de las tropas. También, el aparato militar bélico de Trajano se había diversificado bastante, haciendo al ejército funcional y muy dinámico; un ejemplo particular son los restos arqueológicos de una embarcación romana encontrados en Holanda, en Vechten, que demuestran que sobre el Rin y el Danubio, durante las guerras Dácicas, se utilizaron flotas fluviales para el transporte de tropas y del equipo, o bien para construir puentes de barcas, y proporcionaban un importante apoyo logístico ${ }^{54}$.

$\mathrm{La}$ articulación y funcionamiento del ejército se desarrolló estratégicamente para reforzar la frontera asiática, fundamentalmente por las distancias que separan estos territorios, que los convierten en espacios de frágil seguridad, desde el Golfo de Suez hasta el Mar Negro, fronteras que se extendían a través de unos 1.500 $\mathrm{Km}$, sin una delimitación definida como en el Rin y el Danubio. Por ejemplo, la conexión entre Pelusio, en Egipto, y Gaza, en Palestina, que podía ser cortada fácilmente por los nómades; más al norte también tenía riesgos, producto de la influencia Parta en la zona, a quienes los romanos combatían por sus costumbres y sus peleas internas ${ }^{55}$. Por lo tanto, para Trajano las fronteras debían ser móviles o versátiles, actuando como un dios Jano, bifronte, de guerra y de paz, según fueran los objetivos que se buscaran ${ }^{56}$. Desde este punto de vista, Trajano tenía dos opciones concretas en esta zona oriental: primero incorporarla al imperio militarmente, creando nuevas provincias, o definitivamente olvidarse de aquella región. Desde el 105-106 luchará por la dominación y conquista de esta región extrema, la Arabia Pétrea, con la ayuda del Legado de Siria, Aulo Cornelio Palma. Formó en esta zona un limes adaptado al carácter desértico de la región, facilitando el desplazamiento de tropas y caravanas, e incluso restableciendo el viejo canal que unía el Nilo con el Mar Rojo en el 112, facilitando las relaciones con Arabia e incluso la India, desde donde llegó una embajada a dialogar con Trajano ${ }^{57}$.

Sin desconocer la importancia directa de la guerra en la política de Trajano, no se puede omitir la vertiente diplomática, tendiente a fortalecer sus lazos con los pueblos vecinos. La diplomacia y las relaciones exteriores eran fundamentales para Roma, que las entendía como método persuasivo de conquista, de presión y de expansión, que permitía estrechar o romper vínculos con el exterior, y a su vez permitía hacer prevalecer la ley y los tratados internacionales en beneficio propio ${ }^{58}$. Este modelo jurídico de conquista fue utilizado por Trajano, quien diseña las relaciones exteriores romanas con un abierto móvil expansionista ${ }^{59}$.

so Sánchez, M., op. cit.( El alto imperio), p.62, realiza una buena descripción de los componentes del ejército y sus funciones. Un análisis de la flota en Le Glay, M., op. cit. (La grandeza), pp.19-20, destacando el rol de la marina como garante de la paz, con una misión estratégica y logística. Acompañaba a los convoyes que de Asia, Alejandría, Cartago e Hipona, Tarragona y Cartagena, traían a Pozzuoli y a Ostia el trigo y el aceite, las especias y los productos de consumo diario en Roma, garantizando el desarrollo del comercio libre y transportando ejércitos, armamentos, caballos y las provisiones de las tropas en tierra.

st Le Gall, J., y Le Glay, M., op. cit. (imperio) pp. 363-364.

52 Piganiol, A., "Historia de Roma", Eudeba, Buenos Aires, 1981, p. 283, quien señala que las legiones se reclutaban desde tiempos de Trajano en las mismas provincias en que acampan, para disminuir los costos, aunque implicaban cambios en las estrategias y modos de combates.

s3 Le Gall, J., y Le Glay, M., op. cit. (imperio), p. 364.

54 Al respecto véase a MC. Clees, H., "A military diploma of Trajan", en American Journal of Archaeology, 30 (1926), pp. 418-421, quien resalta a partir de un fragmento de un diploma militar la importancia de las flotas navales en el desarrollo de las expediciones militares de Trajano, y analiza la funcionalidad de cada una de las naves, tal es el caso del tirreme y el quadrirreme. En un estudio más reciente Buono-Core, R., "Flotas militares y guerras navales en el mundo antiguo: el problema del poder naval", en Limes 9-10 (1997-98), Universidad Metropolitana de Ciencias de la Educación, pp.188- 206, presenta un exhaustivo análisis del rol que desempeñaron las flotas navales en los diferentes períodos de la historia griega, hasta tiempos del imperio, facilitando el desarrollo del comercio, junto con la pacificación y romanización de vastas zonas imperiales.

ss Le Gall, J., y Le Glay, M., op. cit. (imperio), esp. p. 367.

s6 Michelotto, P., op. cit. (Aspetti e problemi), pp. 45-55.

57 Respecto a la importancia que Trajano otorga a las relaciones diplomáticas, Plinio el Joven, Panegírico, XXXXVIII, exalta la gran dedicación como método disuasivo y como signo de preocupación por el Estado Romano, como modelo de ciudadano "qué bien sabes recibir y atender a todos", más adelante el mismo Plinio el Joven, Panegírico LXVI,5-6, señala "bella cosa... fue que los aliados y los pueblos amigos acudieran a tu audiencia en su propia patria y en sus propios lugares".

s8 El tema de las relaciones internacionales de Roma, para tiempos de la República es ampliamente estudiado por Silva., J., "Bases teóricas y juridicas de las Relaciones exteriores en Roma, "La Diplomacia y los Tratados Internacionales", en Revista de Historia y Geografia, Universidad de Santiago de Chile, $17(2003)$, pp. 249-273, se refiere en extenso a cómo Roma dirige las relaciones internacionales, utilizando hábilmente las leyes en su propio beneficio, estableciendo tratados internacionales como convenios unilaterales o bilaterales; no obstante que este estudio se enfoca hacia la época republicana, creemos que este método de conquista y expansión es una constante para el resto de la historia romana, y en particular para con los emperadores Trajano y Adriano, que utilizan la diplomacia indistintamente a favor de Roma.

s9 Plinio el Joven, Panegírico, LXVI, 5-6, resalta la forma de conducir las relaciones exteriores por parte de Trajano " bella cosa... fue que los alia- 
Las conquistas y anexiones, tales como la Dacia, imponían una ocupación militar más intensiva de los países danubianos, por cuanto la frontera romana se había hecho mucho más compleja en su extensión y en su estructura $^{60}$. El imperio debía de suministrar al país conquistado una nueva población que lo urbanizara, debía construir caminos, puentes, puertos, y ciudades, situación de alto costo para el Estado romano ${ }^{61}$, no obstante, Trajano asumía que su poder se acrecentaba cuando su imagen se reforzaba, innegablemente que las obras materiales construían y respaldaban su figura.

Esta política imperialista fue seguida por Trajano en el sur y el sureste del imperio, en Parthia, Arabia y Africa, estableciendo vida urbana en regiones desérticas, anexiones que fueron temporales en Mesopotamia, las que provocaron intensas y peligrosas explosiones opositoras en los pueblos de oriente ${ }^{62}$. Si estas conquistas fueron realmente ventajosas desde el punto de vista político y militar, es aún materia de discusión ${ }^{63}$, obligando al posterior repliegue de las legiones romanas.

La megalomanía de Trajano y los éxitos militares fueron logrados a costa de penosos sacrificios de todo el imperio. Desde el punto de vista económico las existencias de plata y oro se redujeron considerablemente con el esfuerzo de las conquistas del extremo oriental del imperio, riquezas que venían desde los inicios del principado $^{64}$. Por otra parte, las operaciones militares no sólo implicaban un enorme gasto militar, sino que también un gasto en vidas humanas, en las legiones que requerían grandes contingentes de soldados, obtenidos de zonas romanas o altamente romanizadas. Los hombres que viajaban a los nuevos países del este y el sur rara vez se repatriaban, muchos perdían la vida en los campos de batalla y otro número de los restantes era empleado en colonizar y urbanizar las provincias de nueva adquisición, desarrollando un largo proceso romanizador ${ }^{65}$.

El botín logrado en Dacia por Trajano, aunque considerable, no bastaba para cubrir los enormes gastos que se generaban con las operaciones militares sistemáticas desarrolladas durante los años del optimus, el incesante movimiento de tropas hacia los teatros de guerra imponía necesariamente la reparación de las viejas vías y la construcción de otras nuevas, la edificación de costosos puentes ${ }^{66}$, la construcción de nuevos barcos, la movilización de innumerables animales de carga con sus correspondientes arrieros, la disposición de alojamientos para los soldados de tránsito en las distintas ciudades, el aprovisionamiento de víveres en diferentes puntos, la provisión de enormes cantidades de armas de todo género, vestidos, calzado ${ }^{67}$ y el establecimiento de guarniciones con un alto $\operatorname{costo}^{68}$.

A este importante gasto de guerra le agregamos las grandes sumas de dinero en Congiaria para el pueblo, donativos para los soldados, juegos y otros espectáculos, los aportes del Estado para la actividad edilicia en

dos y los pueblos amigos acudieran a tu audiencia en su propia patria y en sus propios lugares", destaca la agilidad en la cual atiende a las embajadas que vienen a hablar con el príncipe, Ibidem LXXIX, 6-7, "No hay dificultad para las audiencias, ni retraso en las respuestas, nada obstruye a las embajadas".

60 Aurelio Víctor, De Caesare, XIII, 2.

61 Mazzarino, S., op cit. (L'impero) p. 299, quien se refiere en extenso a que la conquista de la Dacia significó un botín de 5.000 .000 de libras de oro. Estas riquezas fueron rápidamente agotadas con la labor urbanística y benefactora de Trajano, donde edificó el Foro Trajano en Roma, construyó bibliotecas, las Termas de Esquilino, amplió el puerto de Ostia, construyó la vía trajana, restauró la vía Appia, entre otras. Véase Heichelheim, F., Historia social y económica, Rialp, Madrid 1982, p. 91.

62 Rostovtzeff, M., Historia Social y Económica del imperio romano, II, Espasa-Calpe, Madrid, 1972 , p.180.

63 Dumayne, L., op. cit. ( The effect of the Roman), pp. 221-222, aquí se analizan los efectos de la ocupación romana en la población nativa para el caso de Britania, adquiriendo validez para el resto de las conquistas imperiales, dado que el método de dominación no difiere en lo sustancial entre una provincia y otra. Dumayne cree que con la llegada de un ejército o una legión el impacto es potente, pero que permite establecer con prontitud una nueva sociedad, que no es nativa y tampoco es romana, es una sociedad mezclada sometida a un sincretismo cultural desde la llegada del ejército. Finalmente, cree Dumayne que es difícil señalar si fue positivo o negativo el impacto de la ocupación romana, pero concluye que es innegable que al menos modificó la forma de vida de los nativos y romanos.

64 Dion Cassio, LXIX, 7,1, se refiere a "Trajano gastó grandes sumas en guerras y también en trabajos de paz". Heichelheim, F., op.cit., (Historia social), p. 91, sostiene que las pérdidas de $2 / 3$ partes de plata y $4 / 5$ partes de oro del Estado Romano se acrecentaron con las guerras de conquistas desde tiempos de Trajano, y el oro Dácico alivió en parte los problemas financieros que dejaban las guerras trajanas.

65 Respecto a la importancia del ejército en el proceso de romanización, también Bancalari, A., op. cit. (El proceso de romanización), p. 80, quien destaca el rol integrador entre provinciales y romanos, y el reclutamiento provincial desde el siglo I d. de C., constituyéndose en un elemento de integración de las poblaciones locales y a su vez en factor de cohesión en el seno del imperio.

66 Dion Cassio, LXVIII, 13, 1-6.

${ }_{67}$ Rostovtzeff, M., op. cit. (Historia social), p. 223, presenta un interesante comentario de libro Optimus Princeps de Paribeni, E. (año 1929), donde este autor señala que la actividad guerrera y conquistadora que Trajano le impuso al imperio, no reparaba en consumo de energias, y que durante un cierto tiempo los gastos inmensos requeridos por la guerra y la organización de las nuevas provincias fueron cubiertos por el rico botín Dácico y por el producto de las minas de oro y plata de Dacia.

68 Véase a Breeze, D. J. y Dobson, B., "Hadrian's Wall: Some Problems", en Britannia, 3 (1972), pp.182-208, señala que Trajano establece guarniciones en toda la frontera de Britania, y sobre la base de estas guarniciones, Adriano posteriormente construye su muralla, probablemente estos establecimientos precedieron la construcción de fronteras en Britania, lo que hace probable se repitiera en todo el resto del imperio.

Revista de Historia, año 16, vol. 16(1), 2006, pp. 35-46 
Roma $^{69}$, en Italia y las provincias ${ }^{70}$, y la negativa de aumentar los impuestos, evitando medidas impopulares ${ }^{71}$. La situación financiera del Estado Romano no era de las mejores. Indudablemente, que la construcción del poder por parte de Trajano tuvo su soporte en la organización de un imperio evergético universal, sin diferencias, sin embargo, son estas mismas preocupaciones los primeros atisbos de debilidad de su imperio.

En definitiva, pueblos occidentales como los britanos y bárbaros del oriente debieron padecer las intenciones de Trajano, de cambiar el status quo de las relaciones exteriores. Con los britanos por ejemplo, a quienes se les mantuvo en las afuera del imperio, ya se empezaban a establecer guarniciones y fortalezas, donde se construyeron puertas que servían como una especie de control aduanero que permitía la separación entre romanos y bárbaros ${ }^{72}$. Sin embargo, la gran dificultad fue Dacia, que definitivamente se convirtió en un problema estratégico y político ${ }^{73}$, debido a lo difícil que fue someter el espíritu y carácter indómito de este pueblo, con su rey Decébalo a la cabeza, a quien hasta el año 105 se le seguía pagando tributos por parte de Ro$\mathrm{ma}^{74}$; finalmente Trajano venció a este pueblo en la llamada segunda Guerra Dácica, creando una nueva provincia y estimulando la emigración de colonos.

Para conmemorar su victoria en Dacia, Trajano erigió en Roma una columna de 33 metros de altura que aún sigue en pie. En ella se representa la historia de la campaña en un bajorrelieve en espiral que contiene más de 2.500 figuras humanas ${ }^{75}$. Junto con ser un monumento arquitectónico complejo, es una hazaña impresionante de la ingeniería romana, que simboliza la magnificencia de Trajano y cuyo botín fue cuantioso; inmediatamente Trajano estimuló la producción minera de la nueva provincia. Con esta nueva provincia, Dacia será parte de su estrategia militar, proteger mediante la romanización de esta nueva provincia ${ }^{76}$.

La expansión también mejoró la economía romana, y con ello Trajano pudo desarrollar un gobierno de línea evergética ${ }^{77}$, protegió a los huérfanos y a las familias numerosas, estimulando la natalidad ${ }^{78}$, siendo el evergetismo trajano otro símbolo de su poder, aunque los excesos de urbanismo y caridad generaron dificultades económicas.

69 Patterson, J. R., "The City of Rome: From Republic to Empire", Journal Roman Studies, 82(1992), pp.186-215, detalla las remodelaciones arquitectónicas desde tiempos republicanos hasta el imperio, cuyas fuentes han sido los estudios arqueológicos, y los aportes de historiadores, destacando el periodo de los Antoninos de esplendor arquitectónico, se construye el Foro, el campo de Marte, la columna de Trajano, arcos y museos. También Mazzarino, S., op. cit.( L'impero) p. 299.

70 Véase Polverini, L., "Traiano e l'Apogeo dell'impero", en Hispania terris omnibus felicior Premesse ed esiti di un processo di integrazione, Atti del convegno internazionale, Cividale del Friuli, 27-29 settembre 2001, Pisa, Edizioni ETS, 2002, pp. 303-313. Actas que se encuentran disponibles en la versión digital de la Fondazione Niccolò Canussio, cuya dirección es www.fondazionecanussio.org., destacando que la imagen de Trajano en las provincias fue a mejorar las formas de vida urbana, como símbolo de la unidad imperial en la época de los primeros Antoninos. También Solana S. J. y Sagredo S., L., "La política edilicia Viaria en Hispania Durante el Reinado de Trajano", en Hispania Antiqua, XXVI, (2002), Universidad de Valladolid, pp. 60-66, señala que Trajano desarrolló toda una política edilicia en la península hispánica, cuyas fuentes han sido los miliarios, donde se destacan los puentes y las vías, y precisa que entre los años 104-112 se produjo una disminución de esta actividad, presumiblemente producto de la Segunda Guerra Dácica y la Pártica.

71 Trajano económicamente salió a flote con la recolección de los impuestos, a través de los grupos dirigentes, a quienes se les encomendó esta responsabilidad, los conductores eran requeridos posteriormente para pagar la totalidad de lo cobrado. Rostovtzeff, M., op. cit. (Historia social), p. 182. También véase el interesante estudio de Roldán, J. M., Blázquez y Del Castillo, A., op. cit. (Historia) p.199.

72 Véase a Breeze, D. J. y Dobson, B., op. cit. (Hadrian's Wall) p.191, se refieren largamente en los antecedentes fronterizos que Trajano construyó en Britania y que eventualmente sirvieron de base para las fortificaciones Adrianeas.

73 González-Conde, P., "Dacia Provincia: Un Problema para Adriano en el Bajo Danubio", en Scripta Antiqua in Honorem Angel Montenegro Duque et José María Blázquez. Martínez, Universidad de Alicante, Valladolid (2002), pp. 398- 399, quien analiza en extenso la problemática de la Dacia, concluyendo que siempre fue compleja su situación luego de ser incorporada por Trajano.

${ }^{74}$ Le Gall, J. y Le Glay, M., op. cit., (Imperio), esp. p. 365, señalan que Decébalo recibía una subvención anual, considerada como tributo cxorbitante por parte de Trajano, y además tenía a su disposición muchos técnicos e ingenieros romanos que le habian permitido a los Dacios progresar notablemente.

7s Para un análisis detallado de la columna de Trajano la tesis doctoral de Davies, P., "The Politics of Perpetuation: Trajan's Column and Art of Conmemoration", en American Journal of Archaeology, 101, I (1997), pp. 44-65, destaca que toda la columna es un impacto del poder de Roma, y que Trajano está representado ahi como el general más preparado, más idóneo para restaurar y perpctuar la fuerza expansiva de Roma. Más recientemente Lancaster, L., "Building Trajan's Column", en American Journal of Archaeology, 103 (1999), pp. 419-439, se refiere extensamente al valor arquitectónico, el diseño y construcción de esta obra hecha de mármol de luna en 29 bloques de entre 25 y 77 toneladas, levantado hasta 38 metros.

76 Roldán, J. M., Blázquez y Del Castillo, A., op. cit. (Historia de Roma) esp. p. 202.

7 Entendiendo cvergetismo como la preocupación humanitaria, el hacer el bien y el actuar bien sin tener una obligación legal, y el emperador era considerado el primer evergeta del imperio. Cfr. Sartre, M., El Oriente Romano, Provincias y Sociedades Provinciales del Mediterráneo Oriental, De Augusto a los Severos 31-235 d.de C., Akal, Madrid, 1994, pp.156-173. También véase a Gascó, F., "Evergetismo y conciencia cívica en la parte oriental del imperio", en Habis, 26 (1995), pp.177-186, quien señala que los evergetas debian practicar actitudes favorables y benefactoras con las ciudades y las personas, mediante donaciones y la práctica de las virtudes; el evergeta debía ciertamente practicar el patriotismo cívico.

${ }_{78}$ Los alimenta fueron un método de promover la natalidad, y una política benefactora para las clases más pobres, que fortalecía directamente la 
La conquista definitiva de la Dacia entre el 105-106, más allá de contribuir con una importante fuente de riquezas, la consideramos clave en la elaboración de la imagen política e imperialista exitosa de Trajano; su ocupación permitía proteger y defender la inestable frontera danubiana, como primera causa ${ }^{79}$, junto con evitar el revanchismo de su rey Decébalo ${ }^{80}$. La invasión también representó una ardua tarea para el ejército romano y un símbolo inequívoco de la capacidad bélica de éste, debido a la naturaleza del terreno, con gran abundancia de bosques y de relieve montañoso, lo que implicaba enormes dificultades de movimientos, obligando al emperador a mejorar las comunicaciones existentes a lo largo del Danubio, especialmente entre la Pannonia y Mesia, Trajano preparó cuidadosamente el ataque construyendo caminos militares y movilizando las tropas ${ }^{81}$. Sin embargo, la paz conseguida fue efímera y poco consolidada, sin poder reducir el espíritu libertario de los Dacios y de su rey, en Dacia la obra había quedado inconclusa, tanto en lo militar como en lo administrativo, dejando la responsabilidad a Adriano de organizar la zona ${ }^{82}$.

Otro ejemplo glorificador de la obra de Trajano, fue la lucha contra los Partos, en la primavera del $114 \mathrm{~d}$. de C. Trajano inició su ocupación, dominando los territorios del rey Osroes, organizando todo un sistema de reinos vasallos, instalando guarniciones en las ciudades costeras del Mar Negro entre Trapezunte y Dioscurias. Posteriormente se trasladó a la Alta Mesopotamia y, luego del invierno, en el año $115 \mathrm{~d}$. de C. se dirigió hacia el Eufrates y ocupó Europos, estableciendo la provincia de Mesopotamia; en el 116 marchó hacia la parte sur para dominar Asiria y Babilonia y siguiendo el curso de los ríos Eufrates y Tigris realizó una marcha paralela con dos fuerzas, que se unieron en la zona donde ambos se acercan y tomó las ciudades de Selecucia y de Ctesifonte, capital invernal del reino Parto, para finalmente llegar hasta el golfo Pérsico.

La ocupación del imperio en oriente siempre fue una preocupación de Trajano. Geopolíticamente buscó el control y la hegemonía de esta región, especialmente de Armenia ${ }^{83}$, asegurando una línea defensiva del imperio $^{84}$, y buscaba unir con un canal el Eufrates al Tigris y desmantelar ciudades del imperio Parto, para controlar las rutas comerciales con el lejano oriente ${ }^{85}$. Armenia debía ser el punto neurálgico para futuras expediciones bélicas. Para estos fines, creemos que Trajano, si bien es cierto utilizaba la diplomacia como método de dominación, su espíritu guerrero y conquistador lo impulsaba a despreciar la paz en las relaciones exteriores, glorificando su propia res gestae militarmente, por lo que va a expandirse por Asia, Licia y las provincias contiguas hasta Seleucia ${ }^{86}$, con un ejército invencible y poderoso ${ }^{87}$. Así, Partia y Armenia fueron un

imagen del emperador. Respecto a la institución de los Alimenta, se ha escrito bastante, los estudios que hemos revisado son: Santa Cruz, J., "Las Fundaciones Alimentarias y una Carta de Plinio el Joven", en Revista de Estudios Clásicos, I, Madrid (1950-1952), pp.139-143, quien nos explica que éstas eran asignaciones de carácter estable con un fin benéfico y propagandístico destinado a las familias pobres de Italia. Garnsey, P., "Trajan's Alimenta: some problems", Historia, (1968), pp. 369-381, analiza la distribución de este beneficio.

79 Togo, E., "Trajan's Conquest of Dacia", en The American Philological Association, 67 (1936), pp. 83-105, quien cn este artículo analiza y detalla la multicausalidad de la guerra con Dacia, pero esencialmente este autor cree que la posición estratégica es el móvil principal que tiene Trajano.

80 Dion Cassio, LXVIIII, 6,2. También véase Togo, E., op. cit. (Trajan's conquest) p.84, señala que el posible ataque de Decébalo, si bien era posible, el cree que es el pretexto que tiene Trajano para conquistar Dacia y especialmente organizar la conquista de la frontera transdanubiana.

81 Véase Nack, E. y Wägner, W., op. cit. (Roma), p. 451, este autor destaca la forma en que Trajano organiza las tropas en forma estratégica que le permiten organizar la región luego del triunfo militar como provincias, que rápidamente son romanizadas.

8z González-Conde, P., op. cit. (Dacia Provincia), pp. 398-399, quien analiza en extenso la problemática de la Dacia, llegando a concluir que las dificultades de Adriano que lo impulsan a querer abandonar esta simbólica región fueron producto de las dificultades heredadas de Trajano.

83 Véase Petit, P., op, cit. (La paz), p. 29 este autor analiza la discusión entorno a las múltiples causas de la Guerra Partica, y no sólo las pretensiones de Osroes, sostiene que la anexión definitiva de Armenia como la Dacia eran la única forma de acabar con el conflicto.

\$4 Al respecto F. Lepper, op. cit. (Trajan's Parthians), p.129, plantea como tesis de que "la megalomania" de Trajano fue una opinión recogida directamente de Arriano, quien formaba parte de los círculos oficiales de Adriano, quien siempre tuvo la intención de borrar y despreciar las exitosas campañas de Trajano. También Cfr. Lightfoot, C.S., op. cit. (Trajan's Parthians war), Journal Roman Studies, 80 (1990), p.121, nos presenta un interesante estudio de análisis de los objetivos implícitos y subjetivos de las guerras Párticas, donde fundamentalmente plantea la idea de que Trajano lucha contra los Partos sólo por el interés estratégico de Armenia.

85 Le Glay M., Voisin, J., y Le Bohec, Y., Histoire Ramana, Presses Universitaires de France, Paris, 1991, pp. 291-307, esp. p. 298, en capitulo Imperio de los Antoninos, se concluye que las razones para la guerra Pártica son el deseo de gloria de Trajano, y también existen razones de orden estratégico, el deseo de crear una frontera que proteja el Eufrates.

86 Dion Cassio LXVIII 17, 2-3. Respecto a los objetivos de las campañas de Trajano en el oriente, véase Le Glay M., Voisin, J., y Le Bohec, Y., op. cit. (Histoire Romana), p. 280, también destacan las ambiciones personales de Trajano como el principal móvil de expansión en el oriente, Trajano émulo de Alejandro, César y Mareo Antonio. También Angelli B., Ma., "Traiano in Oriente: La Conquista dell'Armenia, della Mesopotamia e dell'Assiria", en González, J. (eds.) Trajano emperador (cit.), pp.12-18, postula que la conquista del oriente por parte de Trajano tiene como único fin el deseo de gloria del emperador, quien desea ser recordado como émulo de Alejandro Magno y que el poner límites significaba ir contra la tradición romana del dominio universal.

87 González, J., op. cit. (Reflexiones en torno la cronología), en González, J. (eds.) Trajano emperador (Cit.) p. 205, En relación a la importancia estratégica de Antioquia para Trajano resultan muy interesantes los análisis de Birley, A., op. cit., p. 97, quien precisa que Antioquia no era el lugar más prometedor para lanzar una expedición hacia alli.

Revista de Historia, año 16, vol. 16(1), 2006, pp. 35-46 
momento clave, donde la egolatría trajana ${ }^{88}$ sobrepasa cualquier estrategia técnica de dominación y conquista, siendo los deseos de gloria el "motor" de su enfermizo imperialismo.

Los símbolos de la grandeza y de poder no sólo se perciben en la organización del ejército, sino que también, en aquellos hechos que reconocen la gloria y majestad de Trajano, tal es el caso de la acuñación de monedas con la leyenda Armenia et Mesopotamia in Potestatem P.R. Redactae. Asimismo los diplomas o certificados que resaltan las capacidades y la gloria del emperador ${ }^{89}$, así como la obtención de títulos, como el de Parthicus o Dácico, e incluso la construcción de figuras póstumas como las estatuas que resaltaban al nuevo Trajano como el sucesor del divino Augusto ${ }^{90}$, todos elementos claves en la recuperación del prestigio militar de Roma ${ }^{91}$. Fiel reflejo del poder y grandeza de Trajano es la Columna Trajana. Obras magníficas que reflejan la grandeza del poder, y que permitieron la construcción de la imagen política.

Trajano, a su regreso a Roma en el 117, está consciente de la inestabilidad política y militar en el oriente por la escasa consolidación; serían a la postre su deuda con el imperio. Su proyecto imperial de empujar las fronteras romanas más allá del Eufrates estaba en serios riesgos, y esta situación lo obliga al establecimiento de estados clientes o estados-vasallos de Roma ${ }^{92}$.

\section{CONCLUSIONES}

La grandeza de Trajano, como hemos analizado, tuvo símbolos concretos: el éxito militar, la tranquilidad y la prosperidad interna a todas luces son el reflejo de un gobierno de beneficencia universal. No obstante, la historiografía coincide en destacar separadamente otros elementos identificadores de la obra de Trajano. Así, tenemos una amplia gama de construcciones edilicias, foros, puertos, puentes, templos, termas, mercados, vías, las instituciones alimentarias, la ampliación del ejército, son símbolos evidentes del poder de Trajano. Siendo en las ciudades donde centró importantes esfuerzos para remodelar y construir todo tipo de obras arquitectónicas que permitieran mostrar la manuficencia de él como príncipe y la grandeza del Imperio, siendo clave en la estructuración local del poder.

Trajano dejó el recuerdo de un emperador excepcional, a quien gustosamente se comparó con Augusto, cuya época se había idealizado en el recuerdo. Desde su muerte, a los sucesores se les decía, imploraba y auguraba ser "más dichosos que Augusto y mejores que Trajano" ". Recuerdo deslumbrante, sobre todo a causa de sus éxitos militares, e indudablemente por su aporte arquitectónico y urbanístico. Sin embargo, no integra ni consolida todas las zonas extremas del imperio, tampoco lo intenta su sucesor Adriano. El ejército de Trajano era de avanzada, y no un ejército de ocupación y protección fronteriza ${ }^{94}$, por lo que su dominación fue

88 Al respecto Lepper, F., "Trajan's Parthians War", en The Classical Review, 63, 3-4, London (1949). Más recientemente Birley, A. (Adriano) op. cit., esp. p. 102, nos muestra la comparación entre los antecesores príncipes que intentaron incorporar a los Partos y Armenios al imperio, y de cómo Trajano aceptó finalmente la denominación de Pártico.

89 Véase a Mac. Clees, H., "A Military Diploma of Trajan", en American Journal of Archaeology, 30, 4 (1926), pp. 419-420, quien a partir de una inscripción correspondiente a un diploma por la brillante actuación de Trajano, logra descifrar la importancia que tenían las flotas navales en las empresas militares romanas en tiempos de los Antoninos.

90 Hanfmann, G.; Vermeule, C., \& Young, W., "A Ncw Trajan", en American Journal o Archaeology, 61,3 (1957), pp. 223-253.

91 Véase Lepper, F., op. cit. (Trajan's Parthians), esp. p.129, quien señala que esta guerra tiene como objetivo inicial la recuperación del prestigio militar de Roma, y en segunda instancia tiene un fin estratégico militar. González, J., op. cit. (Reflexiones en torno la cronologia), en González, J., (eds.) Trajano emperador (Cit.), pp.12-18, un acabado estudio y bastante preciso, debido a que utiliza una cantidad importante de descripciones numismáticas y epigráficas conmemorativas de la época.

22 Sartre, M. El Oriente Romano, Provincias y Sociedades Provinciales del Mediterráneo Oriental, De Augusto a los Severos 31 -235 d. de C., Akal, Madrid, 1994, esp. p. 60, se refiere al concepto de Estado "cliente"o vasallo, quien no comparte este término, él considera que es más apropiado hablar de "Rey o Estado amigo y aliado", ya que ésta es una invención moderna, justificada por la práctica antigua. También véase Bancalari, A., "La Idea de Europa y su Relación con el Mundo Romano Imperial", en Semanas de Estudios Romanos, Universidad Católica de Valparaíso XII (2004), p. 175, quien afirma que Roma genera y construye gradualmente un imperio "no diferenciando entre provincias y pueblos clientes".

93 Eutropio, Breviarum, VIII, 3. "Tanto se ha recordado que hasta nuestro tiempo en el Senado no se aclama a los príncipes de otra manera, sino diciendo más afortunado que Augusto, mejor que Trajano. Hasta tal punto prevaleció la fama de su bondad que ofrece la ocasión de servir como el más destacado ejemplo tanto a los aduladores como a los que alaban sinceramente".

94 Lightfoot, C.S., op. cit. (Trajan's Parthians war) p.123, arqucológicamente son escasos los restos materiales encontrados para la época, en la zona comprendida entre Nísibis, el área norte de Jebel Sinjar en la provincia de Mesopotamia cercana a la ribera del Tigris, tampoco no hay restos de inscripciones que demuestren una presencia romana similar en Asiria, no hay evidencia de ocupación romana durante el periodo de Trajano a lo largo del Eufrates. Birley, A., op. cit. (Adriano), pp. 108-109, plantea que aunque Adriano dio la orden de evacuar totalmente Mesopotamia, Asiria y Armenia Mayor, la realidad es que el territorio recién conquistado había sido entregado por el propio Trajano. Cortés C., J., op. cit. (Un Nuevo Gobierno), en Cortés C., J. M., y Muñiz G., E. (eds) Adriano Augusto (Cit), esp. p.74, señala que para la enorme extensión de territorios adquiridos era imposible conservarlos con el número de tropas y legiones que Roma poseía, además destaca que con la visión política de Trajano de querer siempre extender sus dominios, sólo era posible tener ejércitos de expediciones transitorias, y no ejércitos de ocupación. 
débil, con un control efímero más allá del Tigris y el Eufrates, siendo ésta la gran deuda de Trajano para la posteridad. Pero, definitivamente, con Trajano se cierra un capítulo esencial en la historia romana, la expansión llegaba a su fin y con ello los designios de un "Imperio sine fine" de Virgilio". El imperio se transformará en un imperio con fronteras y límites, dificultades diferentes a la expansión. Desde el 117 en adelante serán otras las claves del poder, la guerra tendrá objetivos y necesidades distintas; Adriano, el sucesor, disfrutará del imperio en la madurez y la gloria.

A la luz de las fuentes, creemos que la laus y la gloria de Trajano, su afán por el poder, lo enceguecen hasta los últimos días de su vida, la gloria fue una obsesión personal más que un proyecto político definido ${ }^{96}$, de la misma forma como le sucedió a su émulo Alejandro Magno. Sin embargo, de acuerdo a los análisis anteriormente expuestos, concluimos que la mayor fuente y símbolo del poder de este emperador, no sólo se encuentra en las obras físicas, arquitectónicas monumentales que logró concretar, sino que esa misma personalidad y estilo fueron los que lo condujeron al extremo de su ambición, convirtiéndose en una clave genuina para comprender sus deseos de grandeza sin límites para él y la propia Roma.

\section{BIBLIOGRAFÍA}

Bancalari M., A. (1997-1998) "Lineamientos para el estudio de la Historia Romana", Limes 9-10

Universidad Metropolitana de Ciencias de la Educación, pp. 170-184.

Bennet, J. 1997. Trajan Optimus Princeps, Life \& Time, London - New York

Birley, A. 2003. Adriano. La biografia de un emperador que cambió el curso de la historia, Península, Barcelona.

Buono-Core V., R. 1996. "La Oceanopolítica y la Geopolítica, ¿Claves para una Comprensión del Expansionismo Romano entre los siglos VI y III a. de C.?", en Semanas de Estudios Romanos, VII-VIII. Universidad Católica de Valparaíso, pp. 57 y 69.

Cizek, E. 1983. L'epoque de Trajan. Circonstantes politiques et problemas ideologiques, Paris.

Christol, M. y Nony, D. 1991. De los origenes de Roma a las invasiones bárbaras, Akal, Madrid.

Giovannini, A. 1986. Oposition et Résistances a lémpire d'Auguste a Trajan, Entretiens XXXIII, en "Fundation Hardt", Vandceuvres- Genéve, pp. 221-236.

González-Conde, M M $^{\mathrm{a}}$ P 1991 La Guerra y la Paz con Trajano y Adriano, Fundación Pastor de Estudios Clásicos, Madrid.

González, J. (eds). 1993. Imp. Caesar Nerva Trajanus Augustus, Sevilla.

González, J. (eds). 2000. Trajano Emperador de Roma. Roma "L'Érma di Bretschneider.

Hammond, N. y Schulard, H. 1989. The Oxford Classical Dictionary, The Clerendon Press, Oxford.

Herrera C., H. 1996 "Principe e imperio en el panegírico de Trajano de Plinio el Joven", en Semanas de Estudios Romanos VII-VIII, Universidad Católica de Valparaíso pp. 277-285.

Hidalgo de la Vega, Mª 1995 El intelectual, la realeza y el poder político, Universidad de Salamanca (eds), Salamanca.

Le Gall, J. y Le Glay, M. 1995. El Imperio Romano. El alto imperio, I, Akal, Madrid.

Montero, S. 1948. De Caliclés a Trajano. Estudios sobre historia política del mundo antiguo, Instituto de Estudios Políticos Madrid.

Michelotto, P. 1994. Aspetti e problema dellétà traiana, Teti Editore, Milano.

Nenci, G., 1992, Límitatio Alexandri, en "Polis", 4 pp. 173-186.

Nicolet, C. 1984. Roma y la Conquista del Mundo Mediterráneo 264-27 a.C. 2. La génesis de un imperio, Labor, Barcelona.

PANI, 1991 "Il Principato Dai Flavi ad Adriano" en Storia di Roma 2, L’imperio mediterráneo. I., principe e il mondo, Einaudi, Torino, pp. 275-276.

Petit, P. 1982. Historia de la Antigüedad, labor, Barcelona.

Sánchez, M. 1998. El Alto Imperio Romano (14 al 235 d.C.), Síntesis, Madrid.

Water, K. 1975 The Reign of Trajan and its place in Contemporary Scholarship (1960-1962), en ANRW II. 2, 381-431.

"Sirgilio, Eneida, I, 278-279. "No pongo a sus dominios límites, en el espacio ni el tiempo. Les he dado un imperio sin fronteras"
"6 Dion Cassio, LXVIII, 19,1 - 20,4.

Revista de Historia, año 16, vol. 16(1), 2006, pp. 35-46 